Journal of Contemporary Educational Research

Research Article

\title{
Reflection on the Quality and Equity of Chinese Basic Education-From PISA 2018 Results: Where All Students Can Succeed
}

Yue Yin

Nanjing Normal University, China

\begin{abstract}
PISA 2018 Results: Where All Students Can Succeed analyzes students' academic performance and wellbeing from the social background of students and schools. It shows that the influence of socio-economic status on the academic performance of students in Beijing, Shanghai, Jiangsu and Zhejiang(China) (hereafter "B-S-J-Z[China]") is relatively low, but disadvantaged students receive insufficient support from school; socio-economic segregation between schools in B-S-J-Z(China) affects students' academic performance and expectations for the future; the shortage of quality teachers in B-S-J-Z(China) is serious, but the teaching resources are sufficient. According to PISA 2018, China should promote balanced development among schools, strengthen teachers' education, adhere to curriculum and teaching reform, so as to promote education equity and improve education quality.
\end{abstract}

Key words: PISA 2018; Basic education; Education quality; Education equity

Publication date: October, 2020

Publication online: 31 October, 2020

*Corresponding author: Yue Yin,1017379935@ qq.com

Since 2000, OECD has launched the Program for International Student Assessment, PISA, testing students what they can do with what they know and linking data from students, schools and systems to compare education outcomes ${ }^{[1]}$.

After years of development, PISA is the most comprehensive, reliable and largest yardstick for horizontal comparison of education quality, equity and efficiency, which has become an influential basis for countries to promote education reform and political action. PISA samples schools and students in each participating country (economy), and tests students' competence in reading, mathematics, science and global literacy through computer tests and questionnaires ${ }^{[2]}$.

In 2015, among UN's 17 Sustainable Development Goals, Quality Education ranked the fourth to ensure inclusive and equitable quality education and promote lifelong learning opportunities for all. PISA 2018 Results: Where All Students Can Succeed (hereafter "Volume II") focuses on equity in education. Volume II examines how students' socio-economic status, gender, immigrant background affect students' performance and wellbeing. In PISA 2018, 15-year-old students in B-S-J-Z(China) made remarkable achievements, ranking the first in 79 countries (economies) in the test. However, the data analysis in Volume II also reflects some problems in China's basic education. We should compare students' performance in B-S-J-Z(China) with other countries, and comprehensively examine the issue of education equity in China.

\section{Analysis on the current situation of educa- tion equity in China}

PISA 2018 points out that education equity does not mean that students have equal outcomes, rather education outcomes are not related to their background (socio-economic status, gender and immigrant background), but are entirely determined by individual efforts. This report not only focuses on students' academic performance, but also on the mediating factors (teacher, school, administrative departments 
and social factors) that affect students' access to schooling, performance, attitudes and beliefs, and their expectations for the future.

Education opportunities are often intertwined with the allocation of education resources, and constantly affect education outcomes. If society can provide students with fair education resources, students can receive equal education regardless of their different backgrounds. From Volume II, we can see:

\subsection{Students' performance related to socio- economic status}

PISA 2018 estimates students' socio-economic status (their family resources and social status) by ESCS index (economic, social and cultural status). PISA 2018 analyzes the relationship between students' ESCS and their reading literacy so as to obtain how ESCS affects education equity. The chart shows that students' performance in B-S-J-Z(China) is outstanding, and their ESCS average (-0.67) is far lower than OECD average (-0.03), which indicates that B-S-J-Z(China) have achieved the highest student performance with lower ESCS.

In addition, disadvantaged students improve academic resilience mainly through self-belief, the support of parents and teachers, and school atmosphere. Students' academic resilience also reflects education equity, but the performance of B-S-J-Z(China) is not brilliant. Students with high academic resilience account for $11.7 \%$, ranking the 38 th. It shows that the development of students' academic resilience in B-S-J-Z(China) is closely related to their socio-economic status. High academic resilience students are more likely to get good development, while disadvantaged students don't receive enough education aid.

\subsection{Students' performance and expectations related to inter-school differences}

Most countries(economies) implement the nearby enrollment policy in basic education, and China's compulsory education is no exception. PISA 2018 measures inter-school differences by calculating the concentration of advantaged and disadvantaged students. Inter-school equilibrium means that students can enjoy undifferentiated school education regardless of their birthplace and residence. If every school has students of different socio-economic status, higher education equity will be achieved. However, PISA shows that B-S-J-Z(China) have large inter-school differences $(42.0 \%)$ and the differences in students' performance are largely caused by their uneven education quality ${ }^{[3-5]}$.

Volume II points out that because of the difference of socio-economic status and household registration, advantaged families and quality teachers tend to choose private schools, so the gap between public and private schools enlarges. To promote education equity, policy makers can think about changing the nearby enrollment policy for students to choose independently.

Due to our population base, each class has more student in disadvantaged schools than in advantaged schools. However, PISA 2018 also points out that small number of students in one class is conducive to teachers' guidance, but not closely related to students' academic performance. Socio-economic status of disadvantaged students will limit their choices, and schools should help students get rid of the family shackles. Other countries' compensatory measures (like Britain, Germany, etc.) to provide additional support for disadvantaged schools are worth learning for China.

\subsection{Students' expectations for future related to teacher and resource differences}

PISA 2018 further notes that inter-school differences are mainly reflected in teacher and resource differences between advantaged and disadvantaged schools. School resources are the basis of education. PISA 2018 uses teacher shortage index and teaching resource shortage index to reflect the allocation of school resources. The results show that though B-S-J-Z(China) ranked the first in student performance, teacher shortage is very serious $(0.75$, ranking the $3 \mathrm{rd})$. The teaching resource shortage index of school in B-S-J-Z(China) is -0.27 , lower than 63 countries (economies), which indicates that B-S-J$\mathrm{Z}$ (China) have sufficient teaching resources.

PISA 2018 evaluates students' expectations for future from two indexes: completing higher education; desired jobs when they are 30 . The expectation of students with different socio-economic status also reflects education equity. In B-S-J-Z(China), huge inter-school difference lies in career-planning curriculum. Disadvantaged schools have scarce career-planning curriculum in B-S$\mathrm{J}-\mathrm{Z}$ (China), far behind advantaged schools. In addition, disadvantaged families also lack the information about career planning, which makes disadvantaged students more difficult to express their career expectations.

\section{Inspiration of PISA 2018 on educational equity in China}


Volume II shows that PISA is highly policy-oriented (Zhao Qian et al., 2019). Based on PISA 2018, we can better understand the current situation of basic education in China, and provide support for students, ensure education quality, and promote education equity.

PISA 2018 affirms the active promotion of China's quality education, and also strengthens our educational confidence: Students from B-S-J-Z(China) have won the first place in 79 countries(economies) in reading, mathematics and science. In addition, the stereotype of exam-oriented education in China used to give foreigners the impression that Chinese students can only take exams, but PISA not only tests curriculum knowledge, but pays more attention to students' ability to use knowledge and solve problems. Therefore, we should be proud of our championship. However, Beijing, Shanghai, Jiangsu and Zhejiang are the four most developed provinces and cities in Chinese education, which cannot fully represent the whole country, especially the Midwest. Therefore, we must face the problems at the same time ${ }^{[3]}$.

\subsection{Enlightenment for the inter-school differences in China}

Narrowing inter-school gap and promoting interschool balance are important policy objectives of education equity in China. B-S-J-Z(China) interschool differences in PISA 2018 remind us that China's education equity still has a long way to go. China's inter-school gap mainly comes from the gap between public and private schools, and between urban and rural areas, and specifically reflected in the shortage of teachers and teaching resources.

Taking the 2015 Shanghai high school entrance examination as an example, Top 10 are all private schools, and the proportion of their students entering key high schools is higher than that of vocational schools. Although the rise of private schools has improved the academic performance of students as a whole, it has damaged the interests of public students to a certain extent (Huang He, 2019). Specifically, the quality of public schools for disadvantaged students is often poor, while advantaged students have more schools to choose. With parents' support, they "flee" from public schools to private schools. As a result, quality students are relatively concentrated in private schools, while poor students go to public schools, which lead to further expansion of inter-school gap.

Recently, though the balanced development of compulsory education in urban and rural areas in
China has made significant progress, PISA shows that the teacher shortage index of B-S-J-Z ranks the third, and shortage of teachers in rural area is particularly serious. This shows that even in the four provinces and cities with the most developed education in China, the problems of insufficient number and low quality of teachers are quite prominent. The number and quality of teachers in other areas may be more severe. The reasons for the shortage in China are: with the liberalization of the two-child policy, the full popularization of compulsory education and the basic popularization of high school education, the demand for teachers is increasing; structural shortages of age, subject, and education, such as teachers' aging; shortage of music, $\mathrm{PE}$ and art teachers, etc.

Teachers should be the primary resource for education development and the cornerstone of national prosperity, rejuvenation and people's happiness. However, in rural areas, due to the restrictions of salary, living environment and professional development, a large number of young and excellent teachers have left rural areas, which aggravates the shortage of rural teachers. Policies like teacher rotation system and public-funded student teachers are beneficial attempts to support rural education, which greatly increases the number of rural teachers and optimizes teacher structure. Only by fundamentally solving the dilemma, and improve the inter-school balance, can we ensure that no matter where students are born, they can enjoy equal and quality education, that is the ultimate policy goal of education equity ${ }^{[6]}$.

\subsection{Enlightenment for the reform of basic education curriculum in China}

With the continuous upgrading of the requirements for talents and their training in the new era, China's overall reform of curriculum and teaching is deepening. PISA 2018 conforms to the trend of world education reform, emphasizing the evaluation of students' reading, mathematics and science literacy, i.e., evaluating students' ability to solve problems by using knowledge and skills in real life, which is consistent with the direction of China's curriculum reform.

First of all, B-S-J-Z are in the forefront of China's economic development and education reform, which meets PISA's requirement for students to answer questions via computer. This is not only the hardware condition for PISA, but also the technical foundation for students to obtain excellent academic performance. The popularity of digital technology provides students with 
unprecedented opportunities for diversified learning as well as diversified risks. The Internet has created conditions for the proliferation of false information and caused great trouble for students to choose and evaluate the quality and reliability of information. Therefore, school education must empower students to screen and adapt to complex information.

Secondly, the comprehensive quality of students can make them better adapt to the challenges of globalization, information technology and knowledgebased economy in the 21 st century. Students' comprehensive quality is an important perspective to investigate education quality. The previous teaching methods in China have long been criticized by many domestic and foreign scholars. With great changes having been taken place to cultivate students in the curriculum reform, the progress still needs concrete evaluation indicators and tools. PISA pays more attention to students' comprehensive quality than the current high school entrance examination in China, and it also notes that the measurement of innovation ability and self-directed development ability should be added in the future, which reminds us to pay attention to students' ability, especially innovation ability and independence.

PISA 2018 results are gratifying to us, but this test only provides some supporting data for China's education quality and equity. Education quality and education equity are two sides of education and cannot be separated. Real confidence of China's education comes from the constant self-examination and selfimprovement. The excellent performance of students in B-S-J-Z is the epitome of our education tradition and reform achievements. However, we still need to learn from domestic and foreign education experience, pay attention to the problem of cultural differences, promote education reform and innovation, and strive to build a fair and quality basic education system, so as to provide students with the ability to think independently and distinguish right from wrong in order to cope with the increasingly complex modern society.

\section{References}

[1] OECD. PISA 2018 Results (Volume II): Where All Students Can Succeed[R]. Paris: OECD Publishing, 2019.

[2] Andreas Schleicher. Beyond PISA: How to Construct school systems in the 21st Century [M]. Shanghai. Shanghai Education Press.2018.

[3] Wang HB. Achievements and Deficiencies in international Perspective: Performance and Enlightenment of FOUR Provinces and cities in China in PISA 2018 [J]. Chinese Journal of Education, 2020(1): 13-20.

[4] Xin T, Jia Y, Li G, et al. Interpretation of PISA2018: Global Vision and China's Performance -- Based on the analysis and international comparison of PISA2018 data of four Chinese provinces and cities [J]. Primary and Secondary School Management, 2020(1): 5-9.

[5] Zhao Q, Zhang JH, Chang YH. Results review and policy implications of the Program for International Student Assessment 2018 [J]. Educational research, 2019, 40(12): 2635.

[6] Jia Y, Zhang JH. Interpretation of PISA2018: Analysis of the Current situation of Chinese teachers' classroom teaching in four provinces and cities -- Based on the analysis of PISA2018 data and international comparison[J]. Primary and Secondary School Management, 2020(1): 16-20. 